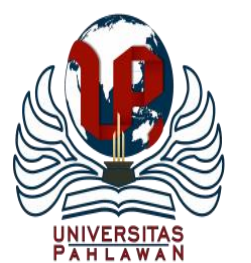

Jurnal Abdidas Volume 2 Nomor 4 Tahun 2021 Halaman 1003-1007

JURNAL ABDIDAS

http://abdidas.org/index.php/abdidas

\title{
Penyuluhan Dagusibu Cara Penggunaan Obat Tetes yang Baik dan Benar pada Posyandu Anggrek Pondok Aren
}

\author{
In Rahmi Fatria Fajar ${ }^{1 \bowtie}$, Iin Hardiyati ${ }^{2}$, Dewi Rahma Fitri ${ }^{3}$ \\ Institut Sains Dan Teknologi Alkamal, Jakarta, Indonesia ${ }^{1,2,3}$ \\ E-mail : Inrahmi14@gmail.com ${ }^{1}, \underline{\text { iin83hardiyati@gmail.com }}{ }^{2}$, dewirahmafitri@gmail.com $^{3}$
}

\begin{abstract}
Abstrak
Masyarakat Indonesia mulai terbiasa menggunakan obat-obatan modern dan didukung informasi secara online dengan tujuan sebagai pengobatan, pencegahan maupun diagnosa suatu penyakit. Kebiasaan baru tersebut menimbulkan suatu dampak positif bagi kesehatan, salah satunya adalah tingkat kepedulian masyarakat terhadap kesehatan. Meningkatnya kepedulian terhadap kesehatan sangat dipengaruhi oleh tingkat pengetahuan tentang kesehatan salah satunya adalah cara penggunaan obat yang rasional. Tujuan dari kegiatan penyuluhan ini adalah dapat memberikan pengetahuan terhadap masyarakat tentang cara penggunaan obat tetes yang baik dan benar agar terhindar dari dampak buruk untuk kesehatan diri maupun lingkungan, menghindari penyimpanan obat yang salah serta pengangganan terhadap obat yang telah rusak. Metode yang digunakan pada kegiatan ini adalah ceramah dan diskusi DAGUSIBU kepada masyarakat di Posyandu Anggrek Pondok Aren. Kesimpulan penelitian yakni bertambahnya pengetahuan masyarakat tentang pengetahuan obat khususnya obat tetes meliputi masa penggunaan obat, penyimpanan dan cara penggunaan obat tetes yang benar.
\end{abstract}

Kata kunci : obat tetes, kesehatan, DAGUSIBU, pengetahuan

\section{Abstract}

Nowdays an Indonesian people are used to modern medication and Supported by online information with the aim of being a medication, precaution, or diagnosis of disease. This new habit has a positive impact on health, which increase the awareness of people to being healthy. The Increased awareness of health is strongly affected by the level of knowledge about health which is rational use of drugs. The purpose of this counseling is to provide a knowledge to people about how to use the drops proper and correctly to avoid the adverse effect on personal and environment health, to avoid the wrong storing of medicine and handling of the damaged medicine. The method was used in this activity is by oral and discussion of DAGUSIBU to community at Anggrek's Integrated Health Care Center in Pondok Aren. The conclusion of this activity is increased the community's knowledge about medicine especially drops including the period of use of drugs, Medicine Storing, and how to use the drops correctly.

Keywords : drops, health, DAGUSIBU, knowledge

Copyright (c) 2021 In Rahmi Fatria Fajar, Iin Hardiyati, Dewi Rahma Fitri

$\triangle$ Corresponding author

Address : Institut Sains dan Teknologi Alkamal

Email : Inrahmi14@gmail.com

ISSN 2721- 9224 (Media Cetak)

DOI : https://doi.org/10.31004/abdidas.v2i4.414

ISSN 2721- 9216 (Media Online) 
1004 Penyuluhan Dagusibu Cara Penggunaan Obat Tetes yang Baik dan Benar pada Posyandu Anggrek Pondok Aren- In Rahmi Fatria Fajar, Iin Hardiyati, Dewi Rahma Fitri

DOI: https://doi.org/10.31004/abdidas.v2i4.414

\section{PENDAHULUAN}

Pengetahuan masyarakat mengenai obatobatan masih sedikit, bahkan minim sekali, walaupun obat-obatan sudah banyak dikonsumsi masyarakat. Obat memiliki peran yang penting dalam kesehatan individu dan lingkungan. Saat ini, banyak sekali pilihan obat yang tersedia untuk menghasilkan efek terapi tergantung pada jenis dan bentuk dari sediaan. Pilihan bentuk sediaan tersebut harus digunakan secara baik agar dapat menghasilkan efek terapi yang optimal (Bidhuan, 2015).

Berdasarkan Undang-undang kesehatan menyatakan bahwa obat merupakan paduan bahan termasuk produk biologi yang dimaksudkan untuk mempengaruhi sistem fisiologi tubuh yang digunakan untuk menetapkan diagnosa, pencegahan, penyembuhan, pemulihan, peningkatan kesehatan dan kontrasepsi manusia (Republik Indonesia, 2009). Profesi yang kompeten dalam penyampaian informasi mengenai obat-obatan adalah apoteker atau disebut juga dengan farmasis (Kemenkes RI, 2016). Peranan apoteker dalam kesehatan di antaranya adalah swamedikasi, konsultasi informasi dan edukasi (KIE) dan monitoring terhadap riwayat kesehatan dari pasien (Kemenkes RI, 2016). Kolaborasi apoteker dengan tenaga kesehatan lain bertujuan agar dapat meningkatkan kualitas hidup dari masyarakat (susi yanti). Hasil survei yang dilakukan menunjukkan bahwa masyarakat belum mengenal apoteker dan farmasis, sehingga pengetahuan informasi obat masih minim. Karena pengetahuan tentang obat masih minim sehingga timbul permasalahan dalam penggunaan obat terutama obat tetes terutama yang memiliki penanganan khusus dalam penggunaan.

DAGUSIBU (Dapatkan, Gunakan, Simpan, Buang) merupakan salah satu program yang diprakarsai oleh Ikatan Apoteker Indonesia yang mempunyai tujuan agar dapat meningkatkan pemahaman dan kesadaran masyarakat mengenai penanganan obat. (Ikatan Apoteker Indonesia, 2014). Hal ini terlihat pada saat survei mengenai penggunaan obat tetes yang tidak tepat.

Polusi udara merupakan penyebab terjadinya gangguan mata. Untuk mengatasi gangguan tersebut masyarakat sering kali membeli obat tetes untuk melakukan pengobatan (Juliyanto et al., 2014). Salah satu cara untuk mengatasi gangguan mata adalaah dengan swamedikasi. Sayangnya, masyarakat kurang paham dalam penggunaan obat tetes mata sehingga keamanan dan khasiatnya tidak terjamin (Juliyanto et al., 2014). Problem mengenai penggunaan obat tetes di antaranya adalah kurang tepat dalam pemakaian obat tetes, cara penyimpanan yang salah dan batas pemakaian obat tetes setelah segel terbuka. Kesenjangan pengetahuan tersebut akan berakibat pengobatan yang dilakukan tidak optimal sehingga menghasilkan efek terapi yang kurang baik.

Pengetahuan penggunaan obat tetes yang rasioanal untuk kesehatan mata, hidung dan telinga merupakan salah satu upaya untuk meningkatkan kesehatan masyarakat. Cara penetesan obat pada mata memerlukan pengetahuan khusus yang mesti disosialisasikan (Kurniawansyah, 2018).

Berdasarkan hasil pengamatan di Pondok Kacang Timur secara umum pengetahuan masyarakat tentang kesehatan masih kurang 
1005 Penyuluhan Dagusibu Cara Penggunaan Obat Tetes yang Baik dan Benar pada Posyandu Anggrek Pondok Aren- In Rahmi Fatria Fajar, Iin Hardiyati, Dewi Rahma Fitri

DOI: https://doi.org/10.31004/abdidas.v2i4.414

khususnya yang berkaitan dengan penggunaan obat tetes untuk mata, hidung dan telinga. Oleh karena itu, akan dilakukan kegiatan penyuluhan DAGUSIBU mengenai pemberian obat tetes yang baik dan benar kepada masyarakat sekitar di Posyandu Anggrek. Kegiatan ini merupakan salah satu Program Pengabdian pada Masyarakat Institut Sains dan Teknologi Alkamal yang melibatkan dosen, mahasiswa, pemerintah desa, tokoh masyarakat, dan kader kesehatan masyarakat Pondok Kacang Timur.

\section{METODE}

Kegiatan Pengabdian Masyarakat dilaksanakan dengan metode pembelajaran beberapa tahap, yaitu sosialisasi persiapan pelaksanaan kegiatan kepada aparatur desa, pelaksanaan penyuluhan yang dilaksanakan di Posyandu Anggrek, monitoring dan evaluasi kegiatan penyuluhan kepada kader kesehatan dan masyarakat.

\section{Tujuan Persiapan}

Pada tahapan sosialisasi kegiatan, tim pelaksana pengabdian memberikan penjelasan kepada kepala desa dan kader kesehatan mengenai tujuan, isi dan susunan acara secara keseluruhan. Kader kesehatan akan melanjutkan informasi tentang kegiatan yang akan dilakukan mengenai penyuluhan tersebut kepada masyarakat.

2. Tahap Pelaksanaan

Pelaksanaan penyuluhan dilakukan dengan metode ceramah dan diskusi oleh dosen dan mahasiswa. Penyampaian materi penyuluhan dengan dibuat beberapa kelompok anggota agar materi tersampaikan dengan baik. Materi yang disampaikan adalah pengobatan rasional menggunakan obat tetes, cara penyimpanan dan penangganan ketika obat rusak.

3. Monitoring dan Evaluasi

a. Struktur

Masyarakat yang menghadiri kegiatan ini berjumlah 25 peserta. Penilaian evaluasi dari kegiatan penyuluhan dilaksanakan oleh kader kesehatan dan tim pengabdian masyarakat. Bahasa yang digunakan dalam pemberian soal menggunakan bahasa umum yang mudah dipahami dan dimengerti oleh masyarakat.

b. Proses

Pelaksanaan kegiatan dimulai pada pukul 09.00 - 11.30 WIB. Evaluasi keberhasilan penyuluhan dengan dibuat kelompok kecil dan dinilai oleh kader kesehatan, mahasiswa dan dosen. Evaluasi dilakukan dengan melakukan sesi tanya jawab dan peragaan kembali oleh anggota pada setiap kelompok untuk mengetahui bahwa materi sudah tersampaikan dengan baik.

\section{HASIL DAN PEMBAHASAN}

Kegiatan pengabdian masyarakat dilakukan oleh dosen, mahasiswa, kader kesehatan dan masyarakat Pondok Aren. Penyuluhan mengenai pengobatan obat tetes yang rasional berlangsung dengan baik dan lancar. Berikut ini merupakan gambar kegiatan penyuluhan. 
1006 Penyuluhan Dagusibu Cara Penggunaan Obat Tetes yang Baik dan Benar pada Posyandu Anggrek Pondok Aren- In Rahmi Fatria Fajar, Iin Hardiyati, Dewi Rahma Fitri

DOI: https://doi.org/10.31004/abdidas.v2i4.414

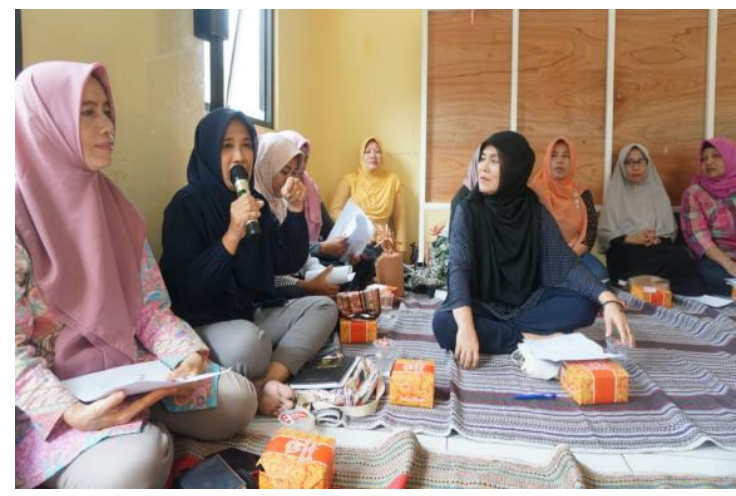

Gambar 1. Pemberian Materi Terkait Obat Tetes

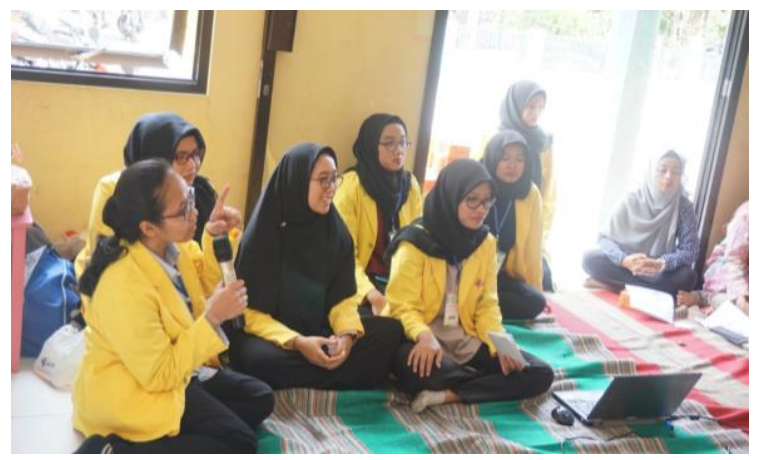

Gambar 2. Pemberian Materi Terkait Obat Tetes

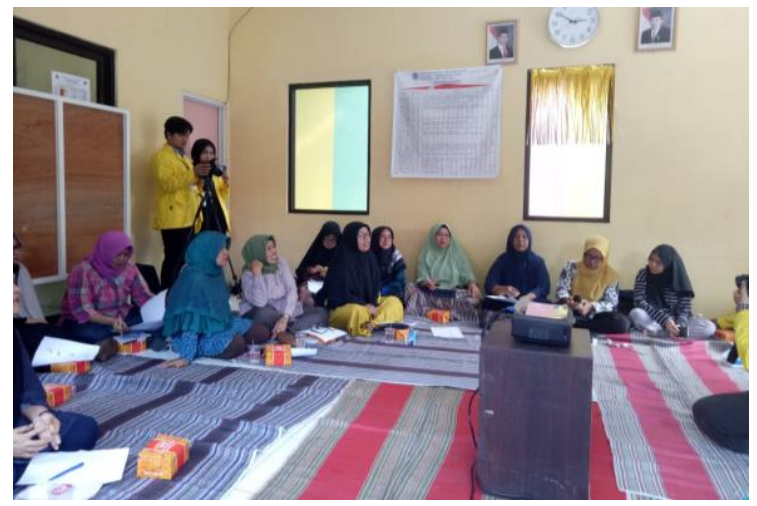

Gambar.3. Peserta Setelah Mengisi Post-test

Berdasarkan hasil diskusi dengan kepala desa diperoleh kesepakatan bahwa kelompok sasaran program pengabdian masyarakat terdiri atas masyarakat dan unsur pemerintah desa, tokoh masyarakat, serta kader kesehatan Posyandu Pondok Aren. Kegiatan yang telah dilaksanakan terdiri atas penyuluhan mengenai penggunaan obat mata yang rasional secara khusus.
Sebagai indikator terlaksananya tujuan dari kegiatan ini, dapat dilihat dari perubahan perilaku dan pengetahuan yang kami rangkum pada tabel 1.

Tabel 1. Indikator Terlaksananya Pengabdian Masyarakat

\begin{tabular}{|c|c|c|c|}
\hline No & Materi & $\begin{array}{c}\text { Sebelum } \\
\text { Penyuluhan }\end{array}$ & $\begin{array}{c}\text { Sesudah } \\
\text { Penyuluhan }\end{array}$ \\
\hline 1 & $\begin{array}{l}\text { Pemahaman } \\
\text { tentang cara } \\
\text { mendapatkan } \\
\text { obat yang } \\
\text { benar }\end{array}$ & $\begin{array}{l}\text { Masyarakat } \\
\text { belum } \\
\text { mengetahui } \\
\text { cara } \\
\text { mendapatkan } \\
\text { obat asli }\end{array}$ & $\begin{array}{l}\text { Masyarakat } \\
\text { mengetahui cara } \\
\text { mendapatkan } \\
\text { obat asli dan } \\
\text { cara mengecek } \\
\text { keaslian obat } \\
\text { tersebut }\end{array}$ \\
\hline 2 & $\begin{array}{l}\text { Pengetahuan } \\
\text { tentang cara } \\
\text { penggunaan } \\
\text { obat tetes }\end{array}$ & $\begin{array}{l}\text { Masyarakat } \\
\text { belum } \\
\text { mengetahui } \\
\text { cara } \\
\text { penggunaan } \\
\text { obat tetes } \\
\text { yang } \\
\text { rasional } \\
\text { sehingga } \\
\text { efek terapi } \\
\text { obat tidak } \\
\text { maksimal }\end{array}$ & $\begin{array}{l}\text { Masyarakat } \\
\text { mengetahui cara } \\
\text { penggunaan } \\
\text { obat tetes yang } \\
\text { benar dan } \\
\text { manfaat dari } \\
\text { obat tetes }\end{array}$ \\
\hline 3 & $\begin{array}{l}\text { Pengetahuan } \\
\text { umur simpan } \\
\text { obat tetes } \\
\text { mata }\end{array}$ & $\begin{array}{l}\text { Masyarakat } \\
\text { belum } \\
\text { mengetahui } \\
\text { lama } \\
\text { penggunaan } \\
\text { obat tetes } \\
\text { mata setelah } \\
\text { dibuka } \\
\text { segelnya }\end{array}$ & $\begin{array}{l}\text { Masyarakat } \\
\text { mengetahui } \\
\text { masa umur } \\
\text { simpan dari } \\
\text { sediaan mata }\end{array}$ \\
\hline 4 & $\begin{array}{l}\text { Pengetahuan } \\
\text { cara } \\
\text { membuang } \\
\text { obat yang } \\
\text { benar }\end{array}$ & $\begin{array}{l}\text { Masyarakat } \\
\text { belum } \\
\text { mengetahui } \\
\text { cara } \\
\text { pembungan } \\
\text { obat yang } \\
\text { benar }\end{array}$ & $\begin{array}{l}\text { Masyarakat } \\
\text { mengetahui } \\
\text { penanganan dan } \\
\text { cara membuat } \\
\text { obat yang rusak } \\
\text { agar tidak } \\
\text { membahayakan } \\
\text { kesehatan }\end{array}$ \\
\hline
\end{tabular}

Hasil pengabdian masyarakat dapat dilihat di bawah ini :

a. Kegiatan penyuluhan ini dihadiri oleh dosen, mahasiswa, aparatur desa, kader 
1007 Penyuluhan Dagusibu Cara Penggunaan Obat Tetes yang Baik dan Benar pada Posyandu Anggrek Pondok Aren- In Rahmi Fatria Fajar, Iin Hardiyati, Dewi Rahma Fitri

DOI: https://doi.org/10.31004/abdidas.v2i4.414

kesehatan dan tokoh masyarakat.

b. Sebelum dilakukan penyuluhan tim pengabdian masyarakat membagikan kuesioner yang berhubungan dengan obat tetes dan diisi oleh seluruh peserta.

c. Peserta penyuluhan sangat antusias mendengarkan pemaparan materi. Terlihat dari diskusi dan pertanyaan yang diajukan oleh peserta.

d. Monitoring dan evaluasi dilakukan dengan cara peserta mengisi post-test dan melakukan pengulangan pemakaian obat tetes oleh seluruh peserta dengan bantuan pengamatan oleh kader kesehatan.

\section{SIMPULAN}

Kegiatan pengabdian masyarakat dengan tema penyuluhan penggunaan obat tetes yang rasional pada Puskesmas Anggrek Pondok Aren berjalan dengan lancar. Kegiatan ini dapat meningkatkan pengetahuan dan kepedulian masyarakat tentang obat, di antaranya cara penggunaan obat tetes, penyimpanan dan masa umur simpan obat tetes, khususnya obat mata setelah dibuka dari segel serta penganganan setelah obat rusak.

\section{UCAPAN TERIMA KASIH}

Terima kasih kami ucapkan kepada mahasiswa, dosen, aparatur desa dan kader kesehatan yang telah memberikan waktu, tenaga dan kontribusi dalam kegiatan pengabdian masyarakat ini.

\section{DAFTAR PUSTAKA}

Bidhuan. (2015). Kumpulan Poster Pesan Apoteker tentang Obat yang Wajib Diketahui.

Ikatan Apoteker Indonesia. (2014). Surat Keputusan Pengurus Pusat Ikatan Apoteker Indonesia Nomor : Kep . 005 / Pp . Iai / 1418 / Iv / 2014 Tentang Petunjuk Teknis Ikatan Apoteker Indonesia.

Indonesia, Kementrian . Kesehatan . Republik.Indonesia (2016). Peraturan Menteri Kesehatan Republik Indonesia Nomor.74 tahun 2016 Tentang Standar Pelayanan Kefarmasian Di Puskesmas.

Juliyanto, T., Mayasari, B. W. C., Widianti, C., Abadi, F. S., Poniwati, K., Fitri, N. A., Sari, R. S., Fatmawati, R. L., Imawan, R., Anggraeni, S. R., \& Madina, U. (2014). Penggunaan dan penyimpanan sediaan topikal multidose untuk mata. Jurnal Farmasi Komunitas, 2(2), 52-56.

Kesehatan, Kesehatan Republik Indonesia. (2016). Peraturan Menteri Kesehatan Republik Indonesia Nomor 72 tahun 2016 Tentang Standar Pelayanan Kefarmasian Di Rumah Sakit. 31-48.

Kurniawansyah, I. S. (2018). Pelatihan Peningkatan Pengetahuan Dan Keterampilan Memilih Obat Mata Bagi Tenaga Kesehatan Desa Cilayung Kecamatan Jatinangor. Dharmakarya, 7(4), 265-268.

Republik Indonesia. (2009). Undang-undang No 39 tahun 2009 Republik Indonesia Tentang Kesehatan. 12-42. 